\title{
AGENT-CAUSATION AND PARADIGMS FOR GOD'S KNOWLEDGE
}

\author{
CHRISTINA SCHNEIDER \\ Ludwig Maximilian University Munich
}

\begin{abstract}
The article aims at formulating a philosophical framework and by this giving some means at hand to save human libertarian freedom (due to 'agentcausation'), God's omniscience (viz.: three paradigms of God's knowledge) and God's 'eternity'. This threefold aim is achieved by 1) conceiving of an agent as having different possibilities to act, 2) regarding God's knowledge - with respect to agents - not only as being 'propositional' in character but also as being 'experiential': God knows an agent also from the 'first person perspective', as the agent knows herself, and, 3), formulating 'eternity' and 'temporality' as being homeomorphically related to each other. This gives rise to a coherent interplay that saves both human libertarian freedom and God's omniscient 'view from eternity'.
\end{abstract}

Agent-causation, and, associated with it, libertarian freedom give rise to several coherence problems. As it seems, the most important one is agent-causation and libertarian freedom embedded in an otherwise 'scientifically' understood universe. Within a physicalistic or materialist framework, the problem is not 'resolvable'. Taking a non physicalistic stance towards 'mental states' or 'persons', however, gives means at hands to resolve the coherence problem. The present article is not about this problem. It can be overcome as the author has shown elsewhere. Rather, the resolution of this problem is presupposed in the present article. From a technical point of view, some models formulated to overcome this problem are used and explicated here. To keep the presentation tight and simple, mathematical details that may be found at other places are largely avoided. Instead, the presentation in this article avails itself of commented pictures.

There is another, much older, coherence problem with libertarian human freedom and so with agent-causation: the relation of God, of His 
omniscience, to human (libertarian) freedom, and, a fortiori, to agentcausation. Albeit this problem naturally does not present itself within a 'physicalist' framework, it is a serious one.

Attempted solutions to this problem tend to have important consequences of how to conceive of God, His 'temporality' or 'eternity', His goodness, His power, His relation to His creation, His independence of His creatures, His 'transcendence', His own freedom, and so on. Attempted solutions may also affect the notion of human freedom itself, as different compatibilist solutions demonstrate. Leibniz' solution, presumably, is one of the historically most famous ones, and it is a 'compatibilist solution'. The Molinist solution is not compatibilist in spirit. Instead, it tries to reconcile God's omniscience and libertarian human freedom. Therefore, it serves in the present article as a starting point.

The present article does not attempt to resolve the problem of agentcausation, freedom and God's omniscience. This would presuppose a refined theory of God and His relation to His creation, not least to clarifying what 'creation' means. It attempts only to indicate a species of knowledge that is both important for God's knowledge of free human acts and somehow overlooked in the contemporary debate - at least, it is not taken as seriously as it deserves. In a slightly different context, however, this kind of knowledge is taken seriously, see, e.g. O'Dea (2002), Perry (2001) and Schärtl (2012). Taking care of this species of knowledge may contribute to conciliating God's omniscience with libertarian human freedom.

The title of the paper uses the word 'knowledge'. A Gettier-style 'definition' of knowledge as 'true, justified belief' is clearly not adequate for God. He has no 'beliefs' - pace open theists of sorts - nor has He to 'justify' anything and what He 'thinks' is 'true', simpliciter. Instead of one or another 'definition' of knowledge, the article exploits only paradigms of knowledge.

The article has five sections. The first sets the stage for the reflections to follow. The second section is about the aforementioned important paradigm of knowledge. The third formulates the relevant features of individuals as agents. The fourth section addresses the question whether this formulation avoids determinism and lawlikeness even in situations of deliberation. Avoiding this, is a criterion of adequacy. These considerations take up again the three paradigms for God's knowledge and serve as a criterion for the viability of the proposals concerning agent-causation made so far. 
The present article takes - at least provisionally - a definite stance towards the 'temporality' or 'eternity' of God. It favours 'eternity', in contrast to authors as e.g. Hasker (1989), Sanders (1998), Boyd (2000), and Rhoda (2011). But it does not argue the issue. Rather, to serve as a second criterion for the adequacy of the proposals made in this article especially those concerning the differences of God's ways of 'knowing' - it formulates a model that combines God's view from eternity on enfolding or acting individuals with respect to temporal order. This is the content of the fifth section. Whether this model implies either solutions or problems with respect to the relevant 'attributes of God' of one or the other sort, may be a topic of further investigation.

\section{A MOLINIST CANVAS}

In recent years, philosophers of the analytic tradition formulate Molina's theory of middle knowledge within the framework of counterfactual conditionals, for a detailed account, see the article of G. Brüntrup und R. Schneider (2011). The formulation is semi-formally as follows:

(1) God knows for each circumstance - C say - how an individual, P, would act, A, if it finds itself in circumstance $\mathrm{C}$.

(2) God 'creates' circumstance C.

(3) P does A.

(4) And, consequently, God knows it.

As it stands, this does not look as if the individual $P$ acts freely. It is God who has the choice among different possibilities (different circumstances) $C$. But, given $C$, the individual does not seem to have alternatives to act. Some authors do not write simply 'God knows for each circumstance - $C$ - how an individual, $P$, would act' but 'God knows for each circumstance, $C$, how an individual, $P$, would freely act'. If 'freely' should be more than philosophical foot-stamping, the individual itself, must be given different possibilities to act for each circumstance $C$, at least. This, however, has consequences with respect to the paradigm under which we conceive of God's 'knowing'.

The Molinist 'solution' is much like the deterministic paradigm of differential equations together with initial conditions. Together they determine uniquely each state of the 'universe', determine uniquely whole histories. God sets the initial condition, the rest follows. One may call this conception of a relevant individual a Leibnizean complete concept. 
In this circumstance, the paradigm of God's way of knowing, is somehow like solving differential equations or at least like logical inferences. Of course, God must not do that step by step, God 'grasps' infallibly the respective relations 'at once'. Metaphors pointing at intellectual activities seem more appropriate than those pointing at sensual activities - as 'seeing. The paradigm of knowledge in this circumstance can be called 'inferential intuition paradigm'. This sounds much like a red herring, but it should indicate the paradigm of (logical) inference on the one hand and that it does not 'take any time' of sorts ('intuition'). This situation, if no other species of 'knowing' is relevant for God's omniscience, hosts problems for human freedom: there is none. But it displays no problems for the attributes one tends to assign to God: Omniscience, a-temporality or 'eternity', immutability. Further, in principle, humans could do the same, they are only restricted in grasping which initial condition is the case, in grasping the complete history; they could be erroneous in their inferences - and all this takes time.

The situation changes if for each of the different conditions, individuals have different possibilities to perform, i.e. different possible histories they may somehow realize: Each condition initiates a myriad of branching possible histories an individual may undergo. The ensuing possible histories do not merge, two different initial conditions may not lead to a common possible episode of their ensuing possible histories. This situation - what initial condition leads to which myriad of branching possible histories - God can know by inferential intuition. But, if $\mathrm{He}$ creates a condition $C^{\star}$, the individual has different possible histories to undergo and it undergoes one and only one thereof. If God knows - and He does by omniscience - which of the possible histories ensues, then the paradigm of inferential intuition, is not appropriate. In this case, the metaphor of 'seeing' seems to be appropriate, as Leftow (1991) argues in his book. The paradigm of knowing the difference of actual and merely possible histories may be called, albeit it is not a fine word, 'observational intuition paradigm'. In this situation, an individual has different ontological possibilities, one of these will be 'actualized. One may call this conception of a relevant individual a possibilistic complete concept (cf. Brüntrup and Schneider 2011) This way of 'knowing', in principle, is also open to humans: of course, they are restricted in what they may 'see', restricted in their empirical access and scope, they may interpret their 'seeings' wrongly, they may be deceived by their senses, and they are prone to diverse empirical fallacies - and all this takes time. 
Is this enough for human freedom? Do these two versions of knowledge exhaust the relevant paradigms?

\section{EXPERIENCE?}

Both paradigms, inferential intuition and observational intuition, are anthropocentric in the aforementioned sense. Of course, as paradigms, they are necessarily bound to a human framework, that is not avoidable. But they are so in a fallacious way: They conceive of God's knowledge of human actions as an external affair - God as an external 'observer', as will become clearer soon. God somehow knows of human actions in principally the same way as do other humans - only 'infinitely more perfect' and 'a-temporally'. Both paradigms point to what often is called 'propositional knowledge'. If they are used with the tacit assumption that what is known by God under the paradigm of inferential intuition or observational intuition or both is all there is to be known - even for an omniscient God - then one conceives of individuals as a Leibnizean or a possibilist complete concepts.

Of course, the 'observational version' raises problems, problems that are disputed: Given the assumption that God has knowledge by inferential intuition of all possible histories an individual may undergo and, given the further assumption that one and only one history is 'actualized' and that only 'created' things may become 'actual', then there are problems concerning the temporality of God, the immutability of God (Does He learn something 'new', when an individual's history proceeds as it does?), the 'causal' relationship between God and its creatures - if there is any - and so on.

What seems hardly (but, see the short remark above) to be questioned is conceiving of God's knowledge as propositional knowledge, as it is indicated by the paradigms above. But, a remark of Thomas Reid's is worth being remembered (Reid 1788, from, Van Inwagen and Zimmerman 1998: 226) in the present context:

From the consciousness of our own activity, seems to be derived, not only the clearest, but the only conception we can form of activity, or the exertion of active power.

This quotation concerning agent causation is not only a very short argument for assuming something like that, it hints to a more general feature of conscious beings of which 'consciousness of activity' or of 'acting' are only cases. The famous dictum/question of Thomas Nagel 
'What it is like to be a bat?' hints more explicitly to this feature: There are experiences of human beings that are authentically and fully transparent to no other human being except to that human being who has it. This does not hold only for the awareness of acting 'now', but also for other experiences - qualia are points in case.

This is not new but of importance concerning the exhaustiveness of the two paradigms of knowing. If there are other non-zombies than the author of this article, then there is more to be known about them than propositional knowledge - as being propositional - can grasp. This kind of knowledge may be called experiential and it is knowledge that may be had only by the individual itself of itself. If God is omniscient with respect to its creation, then He must have authentic knowledge of the different 'what-it-is-like-to-be ... -nesses' of His creatures - as far as they have them. This paradigm of knowledge may be called experiential paradigm. ${ }^{1}$

Of course, this paradigm of knowledge is not restricted to the experience or consciousness of an individual's 'acting now', this experience, however, is related to agent-causation and freedom. If this paradigm of knowledge should be relevant for agent-causation and freedom, individuals that may act in the strong sense of agent-causation must be formulated in contrast to individuals as complete concepts, Leibnizean or possibilist.

\section{INDIVIDUALS AS AGENTS}

As mentioned above, the problem of agent-causation is foremost regarded as a problem concerning the coherence of what might be called the 'inner life' of an individual, or as Lowe (e.g. Lowe 1999: 8) would say, the 'self' and its environment that may be called 'physical'. Given an appropriate model of a 'self' and its environment, the coherence problem may be overcome, as has been argued elsewhere. Crucial for the model is, among other things, that a 'self' or the 'inner life' of an individual is regarded as the coordinated 'bundle' of all its possible histories, one and only one of which will be actualized or brought about by the individual during its 'lifetime'. In this regard, it fits well to the present problem.

${ }^{1}$ To avoid tedious formulations, instead of speaking about 'God's knowledge under the paradigm of inferential intuition, of observational intuition, of experiential knowledge' the phrases 'inferential knowledge', 'observational knowledge' and 'experiential knowledge', respectively, are used. 


\subsection{Modelling Agents}

Depicting the model for one individual, one ends up with a figure like the following:

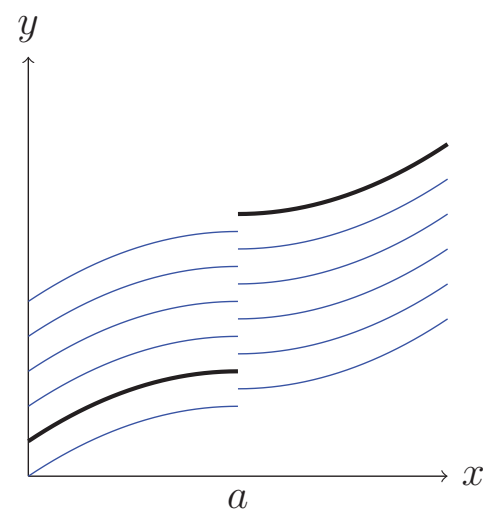

Figure 1

In what respect may it shield from the 'solving differential equations paradigm'? In what respect does it express the act, the bringing about of the individual? ${ }^{2}$

Figure 1 above shows a 'bundle' of lines, depicting different possible histories of one individual. These bundles, however, are interrupted at a point, marked $a$ on the $x$-axis, and the lines on the left side and the right side of this point display, at least visually, discontinuity.

The actual history, depicted boldly in the figure, displays discontinuity of sorts. If one zooms in this figure, one arrives at figure 2:

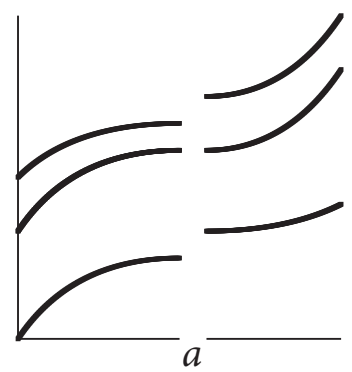

Figure 2

${ }^{2}$ It should be remarked that the model and the figure may be modified as to cope with 'branching histories' also, but this would complicate matters too much and is not important for the present task. 
Here, one sees an exaggeratedly depicted gap on the horizontal axis (henceforth also called $x$-axis) and three 'continuous' lines on the left side of the gap and three on the right side. The middle lines on both sides of the gap seem to be joinable in a 'continuous' manner. The other lines do not. Concerning the 'discontinuous' lines, this means that at the gap an act takes place. The gap indicates a possible act. Concerning the middle lines that may be joined continuously, this is to be interpreted that it is also possible that no act may take place at this locus, better: the individual refrains somehow actively from acting.

Most important, however, is the - exaggeratedly depicted - gap on the $x$-axis separating the right curved lines from left ones. It symbolizes the act. Interpreting the $\mathrm{x}$-axis as 'time', then, at the gap - symbolizing the act - the 'flow of time' is interrupted. That means an act has 'no time', is not an instant of time, nor is it 'at' a time. But it is related to 'time' as there is 'time' before the gap and after the gap; but there is neither a 'last instant of time' before the act nor a 'first instant' afterwards. Mathematically speaking, unduly coarse grained, the phases 'before' and 'after' the act are open (and also closed) sets. In themselves, they are depicted continuously and uninterrupted, symbolizing that in these phases no acts take place. This means that an individual is not and can not be acting 'all the time'.

\subsection{Three paradigms - again}

With respect to the three paradigms of knowledge, three situations, due to acting, can be distinguished. The picture above shows no bold lines but a gap. To 'know' only this, God's inferential intuition would be sufficient. According to that paradigm of knowledge, He may know what histories are possible and 'where' the individual may act. The next figure 3, with bold lines on both sides of the gap, indicates that the individual has been actual at the bold line on the left side of the gap and 'brings about' by acting its continuation on the right side of the gap:

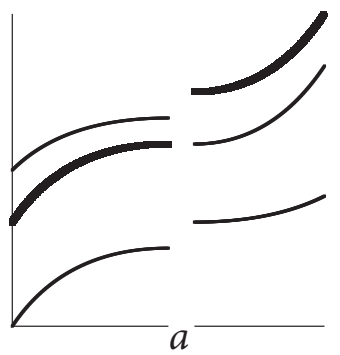

Figure 3 
This situation, taking care of the bold lines, is knowable, both, on the line of observational intuition, focussing only on what is going on 'before' and 'after' the gap. To know that there is a gap, that is that past and future are conjoined by an individual's act or by its refraining from acting and not by a simple performance, is known by inferential intuition. Knowledge, however, of the individual's deliberation process - its intellectual as well as its experiential and emotional aspect - e.g., or knowledge of whether the act was set due to deliberation or due to pure spontaneity, say, is experiential knowledge. This can be had only by the acting individual itself and, due to His omniscience, by God. In this sense, God has a sort of knowledge that is not available to humans other than the acting one in a principle way. Humans do not 'know' 'what it is like to be a bat' or what 'it is like to be another individual'. Experiential knowledge is not grasped by the figure above.

\subsection{What is to Swallow?}

Depicting the possible histories of individuals as lines, i.e. as one dimensional, reduces, of course, individuals to their possible and actual inner lives. This is enough for the present purpose, since acting with respect to an otherwise 'physical' environment is not dealt with in this article.

The possible inner lives are to be interpreted as individuated partly by the different possibilities the environment or - holistically - the universe may realize. They are, partly, the 'psychic' reactions to the different possible environments an individual may find itself in. The other part, the way the individual may react on different environments - differing from individual to individual, even if, strictly speaking impossible, situated in the same environment - belongs to the individual itself. That means, 1) the universe is conceived of as a 'bundle' of possibilities and 2) the inner life of an individual is conceived of as a bundle of possibilities, due to the different environments the individual may find itself in as well as to its internal 'psychic' possibilities to react. One may interpret this that each possible environment co-individuates 'psychic' possibilities of an individual.

The individual is able to act at certain 'instances'. Acting can only ensue from an actual phase. Each act ends up in actualizing both, a possible environment the individual 'wants' to find itself in in the near future and the actualization of its 'psychic' possibilities to react on it internally. The 'continuous' phases between two possible acts may be interpreted as an individual's 'passive' internal responsiveness to its environment. 
Concerning actual inner lives - the bold lines - these are meant to include anything that is relevant for experience, may the source of it be internal or external, may it be 'memory' of its own then actual past as 'memory' - or thoughts. For a finite human individual, experiential knowledge presupposes a minimum of actual awareness of its inner live, albeit unconscious traces of its then actual past and its environment may contribute to the 'shade' of experiences.

Since God is omniscient, His experiential knowledge of His creature's experiences are experientially fully transparent to Him - He has full experiential knowledge of it. He not only 'experiences' what the individual experiences but also any trace that is relevant for an individual's way or 'shade' of experiencing, may it be conscious or unconscious to it. Especially, each experiential knowledge includes experiential knowledge of each past experience of an individual in full transparency.

\section{FREEDOM - DELIBERATION - DETERMINISM AND 'LAW'}

If this model should be viable, the next question is, why should this way of conceiving of an individual as an agent save the libertarian freedom of the individual. In what way does it ban the 'solving differential equation paradigm' or the 'chancy propagation paradigm'? This is the first criterion. The focus will be on 'determinism'.

Famously, van Inwagen once argued that libertarian freedom is inconsistent with both a deterministic universe and an indeterministic one (Van Inwagen 1998, 2002): his consequence argument and his argument from repeated individual histories. Albeit the second argument is flawed on technical reasons, both point at serious problems for libertarian freedom. If the world would be deterministic, humans would be like puppets on a string, if the world would be indeterministic, humans would be like gambling machines of sorts.

The problem with determinism is that there is no libertarian freedom, as it is with indeterminism. The problem with indeterminism shows up when putatively free acts are taken to ensue from rational deliberation. In this case, the argument runs roughly as follows: Even if the relevant individual is faced with different 'ontological' possibilities, a rationally well-deliberated decision aims at a unique situation. This situation 'is brought about' by the ensuing action (presupposing that it is successful as it was planned and wished by the relevant individual) is a consequence not only from the external circumstances an individual finds itself in, but also from his desires, beliefs, experiences, 'memories', 
may they be conscious or not. It is uniquely determined by the history of the individual (its internal as well as its public aspects 'before' the act) and therefore, a rationally and fully deliberated action is a deterministic event of sorts. ${ }^{3}$

In his book Time and Eternity, Brian Leftow tries to demonstrate by examples, that even if

for all agents $\mathrm{S}$ and acts $\mathrm{A}$, even if $\mathrm{S}$ does $\mathrm{A}$ freely, any agent qualitatively identical with $S$ would do A in a situation qualitatively identical with S's (Leftow 1991: 257)

the agent $\mathrm{A}$ is free in that he may have had different alternatives for acting. Whether this should hold for any agent and any situation, may be disputed. It should, however, hold, if the act is fully rational and deliberated. In this case, the whole deliberation process belongs to $S$, and so does the final decision.

If this intuition should be correct, then a difference between the Lewisian counterfactual situation and the situation described by Leftow must be clarified. The Leftownian counterfactual version is associated with the paradigm of 'solving differential equations'. This is the paradigm for lawlike deterministic dependencies. The task for resolving the problem of freedom and deliberation therefore is to formulate the difference between 'uniqueness' and 'lawlikeness'. 'Lawlikeness' generally is assumed to come in two versions: deterministic and indeterministic lawlikeness. Both are in conflict with freedom and deliberation.

So, as indicated above, the question and problem of determinateness of decisions, of rationally fully deliberated decisions, and ensuing acts dwells on the often felt conflict of 'freedom and control'. Is rational deliberation a case of problematic determination, leading to determinism? If this would be the case, then the individual's act was not 'up to it' - some sort of 'internal law' would simply unfold - as the citation of Leftow's above indicates. The individual would be like a complete concept of sorts. An adequate model of agent-causation must avoid this. ${ }^{4}$

The case of unique determinateness by deliberation is a problematic one: Being uniquely determinate by deliberation is in itself not a vice - it is a sign of rationality. But, what does distinguish this unique and definite

${ }^{3}$ D. Lewis may be one of the most prominent adherents of this line of thinking (Lewis 1986: 2-8). Compare also the short analysis of Leftow (1991: 258) concerning the inter-definability of the counterfactual conditional 'might' and 'would', as proposed by Lewis. A more comprehensive overview may be found in Fisher and Ravizza (1998), and Widerker and McKenna (2003). 
decision from a 'lawful propagation', conceived of as a 'deterministic law', prone to the 'solving differential equations paradigm'?

'Lawful' determination is far stronger than uniqueness of a decision to act: At least in deterministic situations, 'lawful determination' implies uniqueness, but not vice versa. What does distinguish 'lawful unique determination' from uniqueness by deliberation?

There are two important paradigms of 'lawfulness' in 'deterministic' contexts: On the one hand, as mentioned above, the paradigm of 'initial conditions, together with laws lead to a unique future state'. On the other hand, the paradigm of 'unfolding somehow like an algorithm', like a computer-program that is executed and exercises a step-by-step 'law of propagation'. The first is at stake here.

The core of lawlike propagation, even with respect to rather liberal assumptions, may be dubbed as 'all in one and always the same principle.' A propagation is 'deterministically lawlike' if there is one 'function' that ties at once all 'instances' or 'states' and 'times' together. This 'function' expresses the law of propagation (in Leibnizean terms: it expresses the complete concept of the individual in question). Formalizing this, leads to something as follows (leaving mathematical detail to one side):

- Let $S$ be the set of 'possible states of an individual' and T or $R$ 'time'.

- Let $\Phi$ be a function $R \times S$ mapping the pairs $(t, s)$ (an instant of times, $t$, and a state, $s$ ) to a (further) state $s^{*}, \Phi(t, s)=s^{*}$. $\Phi$ is the law of propagation. It expresses what state will be reached or has been the case an interval of time of length $|t|$ before or after a state $s$. Further:

$$
\Phi: R \times S \rightarrow S
$$

with $\Phi(0, s)=s$ (to be interpreted as 'being in state's)

and $\Phi(t+r, s)=\Phi(r, \Phi(t, s))$ (this is the 'law of propagation'; it means, e.g., that starting in a state $s$, going, first $t$ 'times' ahead, reaching a state $s$ ",

4 The other variant is that there are several possibilities to act, none of which is definitely chosen - on whatever reasons - by the individual's deliberation. Nevertheless, the individual acts in one of the loosely reflected possible ways and, of course, there is only one actuality to show up. In this case, the individual's acting has something 'chancy'. But this is not a major problem. This situation may well be interpreted as being partly chanceful and of minor rationality. If this situation should be 'stochastically lawful', however, the individual's propagation, its historical way, must then be conceived of as a stochastic process of sorts. The individual would then be like something that may be called 'stochastic' complete concept. This too, must be avoided by an adequate model of agent-causation. 
say, and then, starting in $s$ ”, going $r$ 'times' ahead, ending in state $s^{*}$, say, is the same as starting in $s$ and going $s+r$ 'times' 'at once' ahead).

With this, the following holds:

$$
\left(\exists_{\mathrm{t} \in \mathrm{T}} \Phi(t, s)=\Phi\left(t, s^{\prime}\right)\right) \Rightarrow s=s^{\prime}
$$

If there is a time $t$ and states $s$ and $s^{\prime}$ with $\Phi(t, s)=\Phi\left(t, s^{\prime}\right)$, then $s=s^{\prime}$. This clause reflects that the law of propagation is 'deterministic" - no branching takes place. The graph of the function $\Phi(t, s)$ ( $t$ as variable, $s$ fixed)

$$
\left\{\Phi_{s}: R \rightarrow S, \Phi_{s}(t)=\Phi(t, s)\right\}
$$

corresponds to a possible history. Different possible histories do not intersect and are complete concepts of individuals.

This way of modelling reveals the 'all in one and always the same principle' relevant for 'lawlikeness' - expressed by the function $\Phi$.

In the model presented here, the core of an act is a 'rupture' of sorts, a gap, with respect to its 'past' and, due to topological assumptions, the acts do not happen at 'instants of time.' Therefore, this paradigm is explicitly avoided by the present attempt. Moreover, there is nothing in the model that prevents two exactly equal phases of an individual's histories during the phase 'just before' the act is set, to be 'un-smoothly' continued by two different phases. In both cases, however, the respective choices are unique. ${ }^{5}$

So, the paradigm of 'lawful deterministic propagation' as exploited here, includes very strong further assumptions. If incorporated, it would lead to other models of an individual's 'inner life' - models that would depict intuitions that are hostile to agent-causality and to freedom. Moreover, anything to be 'known' in principle of an individual would be a public affair, propositional knowledge would be enough. In the end, this means, individuals are conceived of as zombies.

Moreover, if the histories of individuals proceed lawlike in the above formulated deterministic way, the only paradigm of knowledge relevant for God's knowledge is inferential intuition. He simply must know $\Phi$ and the condition He creates $-C$. This is a Molinism of sorts.

${ }^{5}$ Albeit not discussed presently, it should be noted that the algorithmic version is not reflected by the model presented in this article either, due to the circumstance that time is topologically not discrete. It would be a discrete version of sorts of the 'all in one and always the same principle' as proposed in the preceding paragraph. It also would be a rather strong further assumption that could only be captured by a strong modification of the model of agent-causation and freedom. 
The model as presented here, faces each individual in its phase 'before' the relevant act with different possibilities to act for. So, if deterministic lawlikeness is blocked by the 'gaps', the question remains, due to the different possibilities open to the individual, whether its acting history is somehow indeterministically or stochastically lawlike. The 'somehow' refers to the assumption that each act and each aim to be acted for is uniquely chosen by deliberation, and so, the probabilities playing a role in indeterministic or stochastic lawlikeness may be degenerate, i.e.: they may have only the values 1 and 0 . And so, one may wonder whether by imposing degenerate probabilities to express the acting uniquely for an aim at each 'gap' lawlikeness is smuggled in. This is not the case. To keep the presentation technically simple, the mathematics relevant for seeing this are not discussed in this contribution.

\section{THE VIEW FROM ETERNITY}

Having considered so far the difference lawlike behaviour makes with respect to simple definite deliberation, this difference should be applied to 'God's view from eternity'. In the preceding section, the difference it makes to the paradigms of knowledge was only hinted at. As will be seen, this difference may be made more explicit. This difference has to do with 'temporality' and 'eternity'.

In advance, however, briefly mentioning the following, more serious problem is necessary: How to formulate or depict what experiential knowledge is about? Or, how to formulate or depict what is going on inside' the acting individual. As noted above, figure 3 does not depict this. And it is not to be depicted somehow, since it is transparent only to God and the relevant individual, not to other human individuals. In short: It is not public. Therefore it can not be formulated or depicted in the public mode. Fortunately, the consequences of this species of 'knowable' and knowledge, especially with respect to temporality and lawlikeness, may be formulated or depicted in a public way, and so, the assumption that the experiences of an individual are in need of a third sort of knowledge on the side of God, and that this sort of knowledge makes a difference that may be qualified.

The following is inspired by the work of Leftow (1991) and Kretzman and Stump (1992) in that it takes up the intuition that what is going on in temporal order within the 'created world' is somehow eternally or a-temporally 'present' in 'eternity', without losing relevant features. 
The most important thing to do for that end is to get rid of a 'natural' temporal order, retaining homeomorphically other relevant structures, on the one hand, and 'knowing' it - by observational or experiential knowledge - 'in eternity', on the other hand. Whether this temporal order is 'knowable' by knowledge conceived of under the paradigm of observational or experiential knowledge makes the difference of 'knowing' a 'temporal' stochastically lawlike going on or a going on 'in time' due to acting by deliberation.

The formal background of the pictures to follow is the so called Alexandroff-Compactifaction. The simplest example thereof, and this is enough for the present model, is that the reals or open intervals thereof are homeomorphic to the circle, omitting the north-pole, say. The mutatis mutandis same holds for the 'lines' depicted in the preceding section.

Depicted homeomorphically on a (here) 'leaf', the whole history due to agency and deliberation comes as a flower:

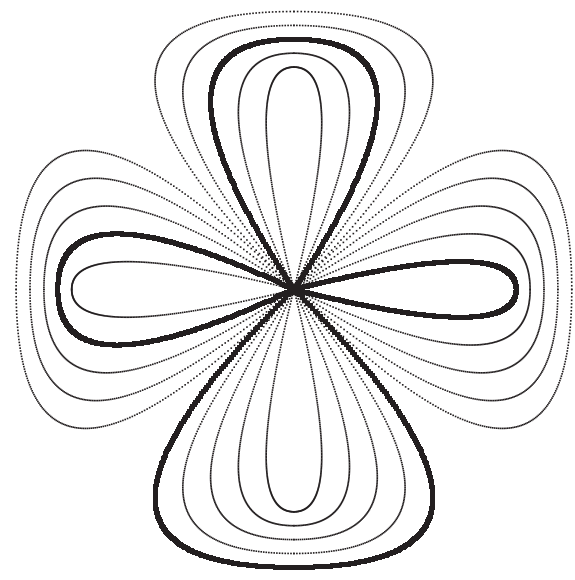

Figure 4

Each leaf of that flower is the situation of one phase of the history. Lines depicted boldly are the actualized possibilities, whereas the light lines are the possibilities not acted for. God 'observes' the difference of possibilities and actualities. But 'observing' is not enough to get the whole history, there is no natural 'temporal' order to be seen. What is the historically first phase? The left leaf? The right leaf? The leaf ahead? Due to the presence of different possibilities, inferential knowledge does not help either. 
The stochastically lawlike situation, however, presents itself differently:

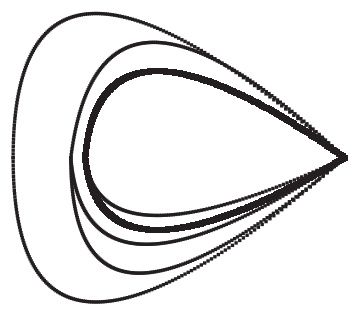

Figure 5

Here, only one leaf is observed - this is due to lawlikeness; the story does not start a new at each phase. But an order may be discerned: As before, there is a difference between possibilities and realizations (these are depicted boldly), but the branchings follow from right to left (anticlockwise), may they be possible or realized. By inferential knowledge of the stochastic laws, it follows that the number of branchings increases as time goes on. And so, by a combination of observational and inferential knowledge, the history is 'known' as it proceeds in temporal order.

Going back to the case of agency: By 'inferential knowledge' it is known that there are four phases and that in each phase one and only one possibility is actualized. Combining this with the observational knowledge of what is actualized, the flower above becomes a bouquet:

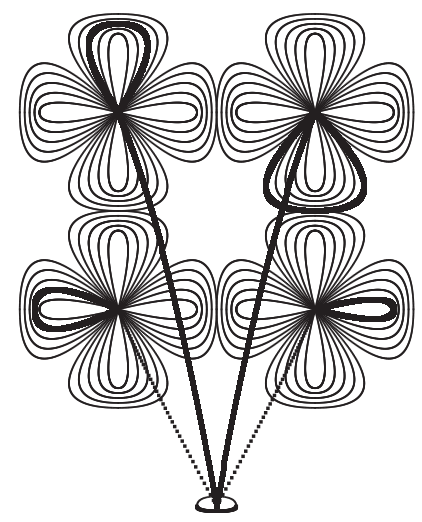

Figure 6

This, however, gives no temporal order. To 'know' the temporal order, experiential knowledge must enter the scene. Due to His omniscience, 
also with respect to His experiential knowledge, God's experiential knowledge of each of the individual's experiences includes in full transparency the experiential past of the individual's experience, may it consciously enter the individual's experience or not. With this, one arrives at the bouquet to follow and to a temporal order, just count the leaves with bold lines in each flower:

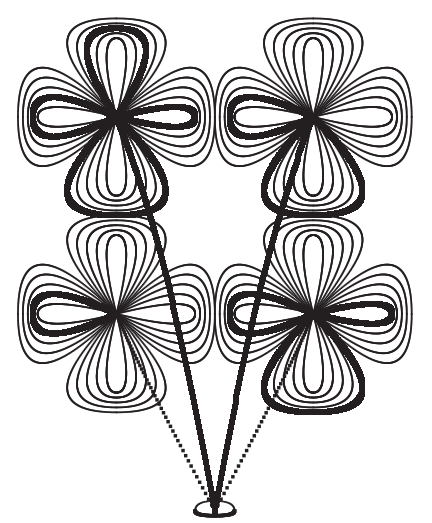

Figure 7

\section{FINALLY, SOME SPECULATION}

As a side-effect, to demonstrate that agent-causation - associated with 'experience' - does make a difference not only for 'temporal' propagation on behalf of created individuals, but also for God's 'eternal' knowledge, a model of how to conceive of the relation of 'temporality' and 'eternity' was presented. As far as the model goes, it shows that both intuitions may be combined coherently. This has consequences not only for agentcausation and God's omniscience, but also for His 'relation to His creation'.

Even if accepting the model of agent-causation and the difference agency makes with respect to 'temporal propagation' and an individual's experience on the one side and God's different ways of being a-temporally omniscient about all this, some philosophers may be inclined to question whether the acts of the individuals, structurally and psychically different as they may be from pure performance, are up to them. In the end, by His unrestricted power, it is God Himself who - by the very act of creation brings about the acts of the created individuals.

A very extreme case of this intuition is Leibniz' theory of the created world as the best of all possible worlds. 'Before' creating, God 'decides' 
which one of the possible worlds $\mathrm{He}$ should create. And so, $\mathrm{He}$ is omniscient with respect to all possible worlds. This omniscience is not restricted to any 'ontological' detail of the possible worlds, it extends to their respective degrees of 'perfection' and 'goodness'. God's perfect knowledge of all these aspects, together with His goodness, ensues in the creation of the (unique!) best of all possible worlds, as Leibniz puts it in his Dialogus: 'Cum Deus calculat et cogitationem exercet fit mundus' (see the present tense!).

In this - as it seems - the world depends in any of its aspects, its performance, as in its sheer existence on God, on His power. Created, due to God's exerting His power - His act - it is extremely one-sided dependent on God, whereas God does not 'depend' in any respect on his creation as created.

Further, tacitly assuming that 'creation' as an exteriorizing of sorts, leads to transcendence driven to its extreme. This has as consequence that God is, what may be called 'metaphysically indifferent' - leaving 'moral indifference' aside - with respect to the created world as being thus 'exteriorized'.

If, however, metaphysical indifference should be blocked - on whatever reasons - while retaining strict immutability and eternity, one may be driven to conceive of the created world, of any of its aspects, its performance, as its sheer existence as being 'encapsulated' 'eternally' in God. This is panentheism of sorts.

With respect to both versions - extreme transcendence and pantheism of sorts - the created world, any of its aspects, its performance, its 'history' is without any remainder, due to His act, and so there is no freedom for relevant individuals, there is no place for human freedom, neither with respect to extreme transcendence nor with respect to a panentheist framework of sorts.

These consequences, if correct, may be overcome. To this end, some intuitions about the 'world' must be revised and some metaphysical speculation may be allowed: The 'world' is not only a 'net of actualities' but it is also a 'net of possibilities', better: 'potentialities. These 'potentialities' are to be conceived of as 'real' or 'ontological' or 'existing. Of course, their way of 'being real' or 'ontological' or 'existing' is different from the way actualities are 'real' or 'ontological' or 'existing. Within this world, individuals are - among other things - coordinated 'bundles' of their respective 'potentialities'. During their life-time, individuals actualize their 'potentialities', leading to a unique actual individual history. For 
this, individuals are not only 'bundles' of potentialities, they must have, among other things, (as e.g. intellect) what may be called 'power', better, following Leibniz: vis activa, to actualize at all. One history and only one history among different potential histories is actualized that way - of course within the framework of their individual potentialities as well as within the framework of the potentialities that co-constitute the embedding 'world'. By this, relevant individuals contribute to the actualization of a 'world history'.

With respect to God's creating the world, one must admit that God creates the framework or 'net' of potentialities. By this, He creates - as substructures - also relevant individuals as coordinated, coherently embedded 'bundles' of potentialities. This is not enough: The vis activa, the power to actualize at all, each relevant individual must have, is also (among other things) due to His creating.

This makes, with respect to what is actualized, relevant creatures 'creative' in a strong sense - but only within the framework created by Him and due to their 'given' vis activa.

That means, on behalf of God's knowledge of actualities, that He can know of them only if they are actualized - and that is due to the creative relevant individuals, exercising their power. But, by being a-temporal and, not least, by His 'experiential knowledge', God's omniscience is preserved unrestrictedly.

The sparse models of the article just wanted to hint at the coherence of God's omniscience with respect to freedom, that is with respect to actualization within the framework of potentialities created by God, strictly due to creatures-within-the-framework-created-by-God. As hinted at above, this attempt is in need of refinement and in need of an embedding and elaborated metaphysical theory, whose core ought to be a 'theory of creation'. And so, some tasks are left - tasks worth pursuing. ${ }^{6}$

\section{BIBLIOGRAPHY}

Boyd, G. 2000. God of the Possible: A Biblical Introduction to the Open View of God (Grand Rapids: Baker Books)

Brüntrup, G., and R. Schneider. 2011. 'How Molinist's Can Have Their Cake and

Eat It Too', in C. e. a. Kanzian (ed.), The Ways Things Are (Frankfurt: Ontos Verlag), pp. 221-241

6 This paper was originally presented in Munich, at a conference for the Analytic Theology Project, generously funded by the John Templeton Foundation. 
Fisher, J. M., and M. Ravizza. 1998. Responsibility and Control (Cambridge: Cambridge University Press)

Hasker, W. 1989. God, Time, and Knowledge (Ithaca and London: Cornell University Press)

Kretzman, N., and E. Stump. 1992. 'Eternity, Awareness, and Action', Faith and Philosophy, 9: 463-482

Leftow, B. 1991. Time and Eternity (Ithaca, London: Cornell University Press

Lewis, D. 1986. 'Counterfactuals and Comparative Possibilities', Philosophical Papers, vol. 2 (New York: Oxford UP), pp. 3-31

Lowe, E. J. 1999. 'Self, agency and mental causation', J. of Consciousness, 6: 225-239 O'Dea, J. 2002. 'The Indexical Nature of Phenomenal Concepts', Philosophical Papers, 31: 169-181

Perry, J. 2001. Knowledge, Possibility and Consciousness (Cambridge: MIT Press) Reid, T. 1788. Essays on the Active Powers of the Human Mind. Cited from Metaphysics: The Big Questions, P. Van Inwagen, D.W. Zimmerman (eds.) (Oxford: Blackwell, 1998), p. 228

Rhoda, A. 2011. 'The Fivefold Openness of the Future', in W. Hasker (ed.), God in an Open Universe: Science, Metaphysics, and Open Theism (Eugene: Pickwick Publications), pp. 69-93

Sanders, J. 1998. The God Who Risks: A Theology of Divine Providence (Downers Grove: InterVarsity Press)

Schärtl, T. 2012. 'The Argument from Consciousness and Divine Consciousness', unpublished, publication in preparation.

Van Inwagen, P. 1998. 'The Mystery of Metaphysical Freedom', in P. van Inwagen, D.W. Zimmerman, Metaphysics: The Big Questions, pp. 365-374

Van Inwagen, P. 2002. 'Free Will Remains a Mystery', in R. Kayne, Oxford Companion to Free Will (Oxford: Blackwell), pp. 158-177

Van Inwagen, P., and D.W. Zimmerman eds. 1998. Metaphysics: The Big Questions (Oxford, UK: Blackwell)

Widerker, D., and M. McKenna, eds. 2003. Moral Responsibility and Alternative Possibilities (Aldershot: Ashgate Publishing) 